\title{
CÁC YẾU TỐ ẢNH HƯỞNG ĐẾN Ý ĐỊNH MUA SẢN PHẨM SÂM NGỌC LINH CỦA NGƯỜI TIÊU DÙNG TẠI TH! TRƯÒ̀NG KON TUM
}

\author{
FACTORS AFFECTING CONSUMER'S PURCHASE INTENTION \\ FOR NGOC LINH GINGSENG PRODUCTS IN KON TUM MARKET
}

\section{Lê Thị Hồng Nghĩa, Nguyễ̂n Tố Nhur}

Ngày nhận bài: 31/10/2019 Ngày chấp nhận đăng: 14/11/2019 Ngày đăng: 05/06/2020

\section{Tóm tắt}

Sâm Ngọc Linh là một loại dược liệu quý, có giá trị kinh tế cao và bắt đầu được các doanh nghiệp phát triển theo hướng đa dạng hóa các chế phẩm từ dược liệu này. Tuy nhiên, các nghiên cứu liên quan đến nhu cầu và ý định mua sản phẩm này hiện nay vẫn chưa được đi sâu nghiên cứu. Bài báo này đã sử dụng lý thuyết hành vi tiêu dùng có kế hoạch (Theory of Planned Behavior- TPB) để xem xét các yếu tố ảnh hưởng đến ý định mua của người tiêu dùng đối với sản phẩm Sâm Ngọc Linh. Một mẫu gồm 176 người tiêu dùng đã được khảo sát bằng bảng phỏng vấn với phương pháp chọn mẫu thuận tiện. Kết quả nghiên cứu cho thấy "Chuẩn mực chủ quan", "Thái độ", "Nhận thức về kiểm soát hành vi” đều có tác động lên ý định mua của người tiêu dùng đối với sản phẩm sâm Ngọc Linh. Đây là cơ sở để cho các doanh nghiệp tiếp cận tốt hơn đến thị trường mục tiêu của mình.

Tù̀ khoá: Sâm Ngọc Linh, ý định mua, TPB.

\begin{abstract}
Ngoc Linh Gingseng is a valuable medicine with high economic value and has been developed by enterprises towards diversifying the products. However, studies related to the need and intention of purchasing this product have not yet been studied in depth. This article has used the Theory of Planned Behavior (Theory of Planned Behavior-TPB) to consider the factors affecting customers' purchase intentions for Ngoc Linh Gingseng products. A sample of 176 responses were collected with the help of a questionnaire survey using an the convenient sampling method. The finding reported that "Subjective norms", "Attitudes", "Awareness of behavior control" all have an impact on consumers' purchase intentions for Ngoc Linh ginseng products. This is the foundation for enterprises to have better access to their target markets.
\end{abstract}

Keywords: Ngoc Linh Gingseng, intention to purchase, TPB.

${ }^{1}$ Phân hiệu Đại học Đà Nẵng tại Kon Tum 


\section{Lời mở đầu}

$\mathrm{Xu}$ hướng tiêu dùng đang ngày càng thay đổi, người tiêu dùng quan tâm nhiều hơn các sản phẩm tốt cho sức khoẻ từ thiên nhiên, vì thế tiềm năng phát triển nhóm dược liệu ngày càng tăng. Để có được các chiến lược phát triển marketing cho sản phẩm dược liệu một cách hiệu quả thì các tổ chức, cá nhân kinh doanh sản phẩm cần phải hiểu rõ được nhu cầu của thị trường, nhận thức của người dùng đối với việc sử dụng các chế phẩm từ dược liệu để tăng cường sức khoẻ, phòng và hỗ trợ điều trị.

Kon Tum là một tỉnh miền núi khu vực Tây Nguyên, có ưu thế về việc phát triển các loại dược liệu và đã được Chính phủ quan tâm, tạo điều kiện phát triển. Tỉnh Kon Tum đã phê duyệt đề án ${ }^{2}$ phát triển vùng trồng, các sản phẩm chế biến từ Sâm Ngọc Linh trên địa bàn thành 1 trong 9 sản phẩm chủ lực. Sâm Ngọc Linh là loại dược liệu quý, được xem như "Quốc bảo" của Việt Nam. Điểm quan trọng làm nên giá trị cao của Sâm Ngọc Linh là trong thành phần có tới 52 loại saponin khác nhau; trong đó có 26 loại saponin có cấu trúc mới, riêng có ở sâm Ngọc Linh.

Với giá bán đắt đỏ và công dụng của nó mang lại cho sức khoẻ, người tiêu dùng hiểu về giá trị của Sâm Ngọc Linh nhưng hiện nay, vấn đề khó khăn là khả năng tiếp cận và sẵn lòng mua sản phẩm. Bài toán hiện nay là cần hiểu được người tiêu dùng của sản phẩm này là ai, và họ lựa chọn sản phẩm là do những yếu tố nào tác động để từ đó có các chiến lược tiếp cận với người tiêu dùng, giúp sản phẩm Sâm Ngọc Linh được sử dụng phổ biến hơn, mang lại giá trị kinh tế cao và bền vững.

Đã có rất nhiều nghiên cứu khoa học trên góc độ kỹ thuật đối với sản phẩm Sâm Ngọc
Linh được thực hiện. Tuy nhiên, đứng trên góc độ tiếp cận của thị trường và từ phía người tiêu dùng sử dụng sản phẩm thì chưa có nhiều nghiên cứu để xác định các yếu tố ảnh hưởng đến quyết định sử dụng sản phẩm thảo dược này.

\section{Co' sở lý thuyết và giả thuyết nghiên cứu}

\subsection{Co' sở lý thuyết}

Nghiên cứu về lý thuyết ý định mua của người tiêu dùng không thể không nhắc đến một số mô hình như: mô hình thái độ đa thuộc tính (Martin Fishbein, 1980), mô hình thuyết hành vi hợp lý (Fishbein và Ajzen, 1975), mô hình thuyết hành vi có kế hoạch (Ajzen, 1985). Kế thừa những nghiên cứu ở các lĩnh vực tương tự đã thực hiện, tác giả sử dụng lý thuyết hành vi có kế hoạch (Theory of planned behaviorTPB) (Ajzen, 1991) là lý thuyết mở rộng của lý thuyết hành vi hợp lý (Theory of reasoned action- TRA) (Fishbein và Ajzen, 1975). Đây là mô hình nghiên cứu được chấp nhận và sử dụng rộng rãi khi nghiên cứu về ý định mua của người tiêu dùng áp dụng cho các nghiên cứu về mối quan hệ giữa niềm tin, thái độ, ý định hành vi trong các lĩnh vực khác nhau như thương mại, chăm sóc sức khỏe, hệ thống thông tin, quảng cáo, v.v... Theo đó, mô hình lý thuyết hành vi có kế hoạch cho rằng ý định là nhân tố chính dẫn đến hành vi, nó là chỉ báo cho việc con người sẽ cố gắng đến mức nào, hay dự định sẽ dành bao nhiêu nỗ lực vào việc thực hiện một hành vi cụ thể. Trong lý thuyết này, ý định thực hiện chịu ảnh hưởng bởi ba nhân tố: (1) thái độ đối với hành vi, (2) chuẩn mực chủ quan và (3) nhận thức về kiểm soát hành vi. Trong đó, thái độ là đánh giá của một cá nhân về kết quả thu được từ việc thực hiện một hành vi, nó có thể là đánh giá tích cực hoặc tiêu cực đối với hành vi thực hiện; chuẩn mực chủ quan là ảnh hưởng của xã hội, đề cập đến áp lực xã hội đối với

\footnotetext{
${ }^{2}$ Quyết định số 31/2018/QĐ-UBND ngày 14/11/2018 sửa đổi, bổ sung khoản 1 và khoản 2 điều 1 của Quyết định số 29/2011/QĐ-UBND ngày 26/9/2011 của UBND tỉnh Kon Tum về việc phê duyệt "Đề án xây dựng và phát triển các ngành kinh tế mũi nhọn và sản phẩm chủ lực của tỉnh đến năm 2020”.
} 
việc thực hiện hay không thực hiện một hành vi; nhận thức về kiểm soát hành vi được định nghĩa là cảm nhận của cá nhân về việc dễ hay khó khi thực hiện hành vi [1, tr.188].

Một số nghiên cứu trong các lĩnh vực thực phẩm như nghiên cứu Chiew Wee và cộng sự (2014) áp dụng lý thuyết hành vi có kế hoạch nhằm kiểm tra nhận thức của người tiêu dùng, ý định mua hàng và hành vi mua thực tế và mối liên hệ giữa chúng trong bối cảnh các sản phẩm thực phẩm hữu cơ. Kết quả chỉ ra rằng ý định mua thực phẩm hữu cơ là chịu ảnh hưởng đáng kể từ nhận thức của người tiêu dùng về các yếu tố an toàn, sức khỏe, môi trường và phúc lợi động vật của sản phẩm. Trong khi đó, nghiên cứu này lại chỉ ra rằng nhận thức của người tiêu dùng về chất lượng của sản phẩm hữu cơ thì lại không có tác động đến ý định mua sản phẩm. Về mặt lý thuyết, nghiên cứu này ủng hộ quan điểm của người tiêu dùng về nhận thức đối với các sản phẩm thực phẩm hữu cơ sẽ ảnh hưởng đến ý định mua của họ và sau đó dẫn đến mua thực tế của sản phẩm. Những phát hiện đề xuất thông tin hữu ích cho các nhà tiếp thị hữu cơ để giúp họ phát triển các chiến lược tiếp thị hiệu quả để thuyết phục quan tâm đến phân khúc mua các sản phẩm thực phẩm hữu cơ và để nâng cao môi trường thân thiện hành vi mua hàng ở Malaysia. Cũng trong lĩnh vực hàng tiêu dùng đắt tiền, Sheetal và cộng sự (2017) đã nghiên cứu hành vi tiêu dùng của người Ấn Độ dựa trên lý thuyết hành vi có kế hoạch về thời trang xa xỉ để xác định các yếu tố ảnh hưởng đến ý định mua hàng xa xỉ và hành vi mua hàng xa xỉ giữa những người tiêu dùng Ấn Độ; hiểu mối quan hệ giữa người tiêu dùng, ý định mua hàng và các biến như thái độ, chuẩn mực chủ quan và nhận thức về kiểm soát hành vi liên quan đến việc mua hàng thời trang xa xỉ; đánh giá sức mạnh tương đối của chuẩn mực chủ quan so với thái độ đối với lĩnh vực nghiên cứu. Kết quả nghiên cứu chỉ ra rằng chuẩn mực chủ quan là yếu tố quyết định quan trọng nhất đến ý định mua hàng, thái độ được coi là yếu tố quan trọng thứ hai và mối quan hệ giữa nhận thức về kiểm soát hành vi và ý định mua trong mô hình nghiên cứu là không đáng kể. Hay một nghiên cứu khác của Dongmin Lee và cộng sự (2012) nắm bắt các đặc điểm nhân khẩu học, hành vi mua, hành vi sau khi mua, và đặc điểm lối sống theo nhóm người tiêu dùng cho kết quả mua sâm tươi theo ba yếu tố: yếu tố đặc trưng vật lý, yếu tố an toàn và yếu tố thông tin chỉ dẫn canh tác.

Tại Việt Nam, nghiên cứu về yếu tố ảnh hưởng đến ý định mua cũng đã được thực hiện rất nhiều nhưng đối với lĩnh vực dược liệu đặc biệt là Sâm - một loại dược liệu có giá thành cao và chất lượng cao cho sức khoẻ thì còn hạn chế. Vì vậy, nghiên cứu này tập trung xem xét sự tác động của các yếu tố thái độ, chuẩn mực chủ quan và nhận thức của người tiêu dùng đến ý định mua đối với loại dược liệu quý hiếm.

\subsection{Giả thuyết nghiên cúu}

Úng dụng nghiên cứu đối với trường hợp Sâm Ngọc Linh sử dụng yếu tố thái độ đối với hành vi là sự sẵn sàng tinh thần vĩnh viễn thu được từ kinh nghiệm, tạo ra ảnh hưởng trực tiếp hoặc năng động đến phản ứng của từng cá nhân đối với các đối tượng và tình huống được tiếp xúc (Allport, 1935). Trong trường hợp thái độ đối với một hành vi nhất định, mỗi niềm tin liên kết hành vi với một kết quả cụ thể, hậu quả hoặc một số thuộc tính khác. Vì mỗi thuộc tính được đánh giá trước là tích cực hoặc tiêu cực (thành phần cảm xúc của thái độ), do đó, hành vi được tự động coi là mong muốn (nếu nó có kết quả chủ yếu là tích cực) hoặc không mong muốn (nếu nó được liên kết với các kết quả chủ yếu là tiêu cực). Trong trường hợp này yếu tố thái độ đối với hành vi là đánh giá tiêu cực hay tích cực về việc sử dụng Sâm Ngọc Linh. Các nghiên cứu trước đây cho rằng giữa thái độ đối với hành vi và ý định có mối quan hệ thuận chiều (Marija Ham và cộng sự (2015) và Sheetal Jain, Mohammed Naved Khan, Sita Mishra (2017). Vì vậy giả thuyết nghiên cứu được đề xuất là: 
H1: Thái độ đối với hành vi của người tiêu dùng có ảnh hưởng tích cực lên ý định mua sản phẩm Sâm Ngọc Linh.

Các chuẩn mực chủ quan đề cập đến niềm tin rằng một người hoặc một nhóm người quan trọng sẽ phê duyệt và hỗ trợ một hành vi cụ thể. Các chuẩn mực chủ quan được xác định bởi áp lực xã hội nhận thức từ người khác để một cá nhân cư xử theo một cách nhất định và động lực của họ để tuân thủ những quan điểm của những người khác (Marija Ham và cộng sự, 2015). Kết quả chuẩn mực chủ quan là ảnh hưởng của xã hội để thực hiện hay không thực hiện hành vi, điều đó có nghĩa rằng Sâm Ngọc Linh sẽ có tác động thuận chiều hay ngược chiều đến ý định mua. Một mối quan hệ tích cực giữa chuẩn mực chủ quan và ý định đã được thành lập bởi một số nghiên cứu (Fishbein và Ajzen, 1975; Ajzen, 1991; Kim và Karpova, 2010). Vì vậy giả thuyết nghiên cứu được đề xuất là:

H2: Chuẩn mưc chủ quan có ảnh hương tích cực lên ý định mua sản phẩm Sâm Ngọc Linh.

Nhận thức kiểm soát hành vi phản ảnh việc dễ hay khó khăn khi thực hiện hành vi, biến này đề cập đến sự hiện diện của các tài nguyên và cơ hội cần thiết cho một hành vi cụ thể và bị ảnh hưởng bởi một số yếu tố, chẳng hạn như kinh nghiệm trước đó liên quan để mua các sản phẩm, nhận thức tiện lợi, tiền tệ; nhận thức các rào cản; nhận thức rào cản thời gian và các yếu tố khác làm tăng hoặc giảm mức độ khả thi của hành vi này. Các cấu trúc này, được xem xét cùng nhau, xác định ý định của cá nhân và cuối cùng dự đoán hành vi. Do đó, dựa trên đánh giá của các tài liệu, giả thuyết nghiên cứu được đề xuất là:

H3: Nhận thức về kiểm soát hành vi có ảnh huởng tích cưc lên ý định mua sản phẩm Sâm Ngoc Linh.

Yếu tố thái độ về hành vi kết hợp các chuẩn mực chủ quan và nhận thức kiểm soát hành vi càng lớn, ý định cho hành vi định hướng môi trường càng mạnh mẽ. Ngoài ra, một số nghiên cứu tương tự có sử dụng các biến nhân khẩu học xã hội (Phuah và cộng sự, 2012), nhận thức về sức khỏe (First \& Brozina, 2009; Michaelidou \& Hassan, 2008; Salleh và cộng sự, 2010), và kiến thức tham khảo (Amran \& Nee, 2012; Saleki và cộng sự, 2012) điều này phụ thuộc vào sự sẵn có của các nguồn lực và các cơ hội để thực hiện hành vi. Do đó mô hình nghiên cứu được dựa vào lý thuyết nêu trên kết hợp các công trình nghiên cứu tương tự về ý định mua của người tiêu dùng tác giả đã đề xuất mô hình:

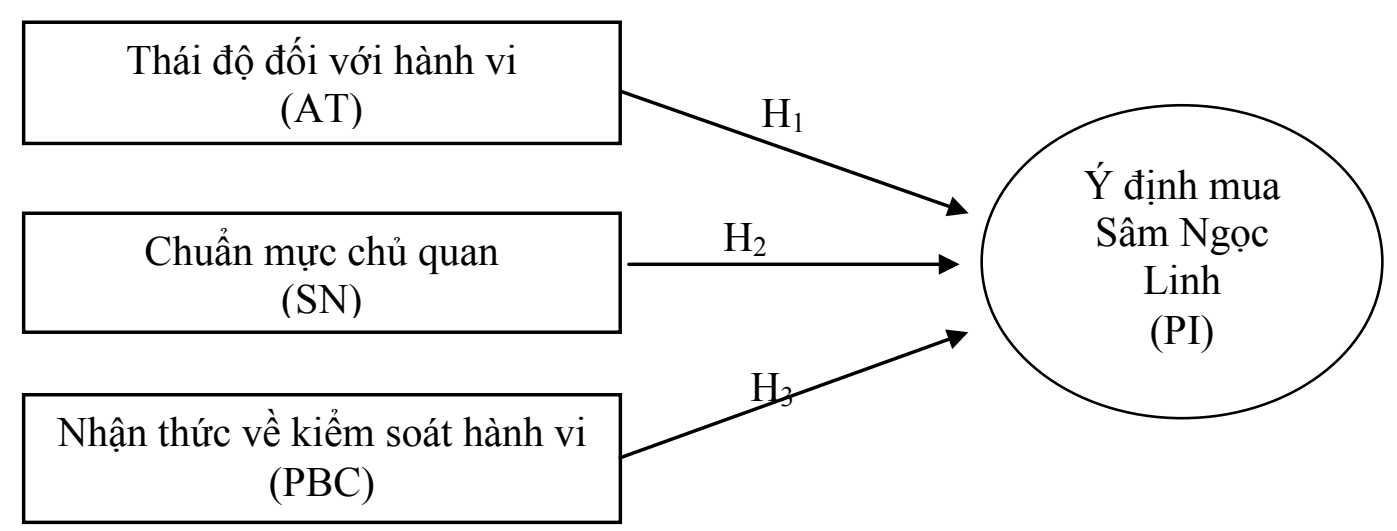

Nguồn: Tác giả đề xuất

Hình 1. Mô hình nghiên cứu 


\section{Phương pháp nghiên cứu}

\subsection{Nghiên cứu định tính}

Nghiên cứu định tính được thực hiện bằng việc nghiên cứu sơ bộ ban đầu sau đó phỏng vấn trực tiếp và thảo luận nhóm 8 người tiêu dùng trên 18 tuổi sinh sống tại Kon Tum để xây dựng các thang đo và xây dựng bảng khảo sát. Sau đó, tiếp tục phỏng vấn thử 30 người tiêu dùng để hiệu chỉnh thang đo và đưa ra 11 biến quan sát dùng để đo lường các yếu tố tác động đến ý định mua của người tiêu dùng đối với sản phẩm Sâm Ngọc Linh. Thang đo chính thức của nghiên cứu chủ yếu dựa trên thang đo của Marija Ham và cộng sự (2015) và Sheetal Jain, Mohammed Naved Khan, Sita Mishra (2017) và một số biến quan sát phát triển từ nghiên cứu định tính sơ bộ.

\subsection{Nghiên cứu định lựng}

Nghiên cứu định lượng thông qua khảo sát chính thức 200 người tiêu dùng. Thông qua kết quả của bảng câu hỏi, tác giả tiến hành mã hóa các biến và sử dụng phần mềm SPSS 20.0 xử lý số liệu kiểm định độ tin cậy của thang đo, phân tích nhân tố khám phá và phân tích hồi quy nhằm xác định các nhân tố ảnh hưởng tới ý định mua của người tiêu dùng. Trong tổng số 200 phiếu khảo sát được phát ra, có 24 phiếu không thực hiện đầy đủ yêu cầu khảo sát nên bị loại. Số phiếu hợp lệ là 176 phiếu được đưa vào phân tích. Thời gian tiến hành thu thập dữ liệu từ ngày 01/08/2019 đến ngày 15/09/2019.

\section{Kết quả nghiên cứu}

\subsection{Thống kê mô tả mẫu theo biến kiểm soát}

Bảng 1. Thống kê mô tả dữ liệu

\begin{tabular}{|l|l|c|c|}
\hline \multicolumn{2}{|c|}{ Đặc điểm của mẫu (n= 176) } & Số lượng (Người) & Tỷ lệ (\%) \\
\hline \multirow{4}{*}{ Giới tính } & Nam & 93 & 52.84 \\
\cline { 2 - 4 } & Nữ & 83 & 47.16 \\
\hline \multirow{4}{*}{ Độ tuổi } & $18-25$ tuổi & 8 & 4.5 \\
\cline { 2 - 4 } & $26-35$ tuổi & 86 & 48.86 \\
\cline { 2 - 4 } & 36-54 tuổi & 49 & 27.84 \\
\cline { 2 - 4 } & Hơn 55 tuổi & 33 & 18.8 \\
\hline \multirow{4}{*}{ Trình độ học vấn } & Tốt nghiệp THPT & 6 & 3.4 \\
\cline { 2 - 4 } & Trung cấp/Cao đẳng & 54 & 30.68 \\
\cline { 2 - 4 } & Đại học & 98 & 55.68 \\
\cline { 2 - 4 } & Sau đại học & 18 & 10.24 \\
\hline \multirow{3}{*}{ Thu nhập } & $<5$ triệu & 30 & 17.04 \\
\cline { 2 - 4 } & $>5-10$ triệu & 70 & 39.77 \\
\cline { 2 - 4 } & $>10-15$ triệu & 53 & 30.11 \\
\cline { 2 - 4 } & $>15$ triệu & 23 & 13.08 \\
\hline
\end{tabular}

Nguồn: Tác giả điều tra và phân tích, 2019

Kết quả thống kê cho thấy trong số 176 người được khảo sát có $52.84 \%$ là nữ, $47.16 \%$ là nam. Trong đó, độ tuổi tập trung chủ yếu là 26 đến 54 tuổi, phần lớn trình độ ở mức Trung cấp/ Cao đẳng và Đại học, thu nhập từ 5-15 triệu.

\section{2. Đánh giá thang đo bằng hệ số Cronbachs Alpha}

Để đánh giá chất lượng của thang đo, nghiên cứu sử dụng 2 công cụ chủ yếu là phân tích 
nhân tố EFA và kiểm định Cronbach's Alpha. Trong đó, độ tin cậy và tương quan giữa các biến quan sát trong thang đo được đánh giá qua hệ số Cronbach's Alpha.

Bảng 2. Độ tin cậy của thang đo

\begin{tabular}{|c|c|c|c|c|}
\hline Biến quan sát & $\begin{array}{l}\text { Trung bình } \\
\text { thang đo } \\
\text { nếu loại biến }\end{array}$ & $\begin{array}{l}\text { Phương sai } \\
\text { thang đo } \\
\text { nếu loại biến }\end{array}$ & $\begin{array}{l}\text { Tương } \\
\text { quan biến } \\
\text { - tổng }\end{array}$ & $\begin{array}{l}\text { Cronbach } \\
\text { Alpha nếu } \\
\text { loại biến }\end{array}$ \\
\hline \multicolumn{5}{|c|}{ Thái độ (Cronbach's Alpha =0.738) } \\
\hline $\begin{array}{l}\text { AT1: Thái độ của tôi đối với việc mua } \\
\text { Sâm Ngọc Linh là tích cực }\end{array}$ & 7.00568 & 2.611 & .498 & .726 \\
\hline $\begin{array}{l}\text { AT2: Sâm Ngọc Linh là sản phẩm đáng } \\
\text { giá }\end{array}$ & 6.99432 & 2.509 & .587 & .625 \\
\hline $\begin{array}{l}\text { AT3: Sâm Ngọc Linh là sản phẩm rất có } \\
\text { lợi cho sức khoẻ }\end{array}$ & 7.27273 & 2.245 & .607 & .598 \\
\hline \multicolumn{5}{|c|}{ Chuẩn mục chủ quan (Cronbach's Alpha =0.719) } \\
\hline $\begin{array}{l}\text { SN1: Hầu hết những người quan trọng } \\
\text { với tôi nghĩ rằng tôi nên mua Sâm Ngọc } \\
\text { Linh }\end{array}$ & 10.40909 & 4.963 & .472 & .679 \\
\hline $\begin{array}{l}\text { SN2: Nhiều người xung quanh tôi có sử } \\
\text { dụng Sâm Ngọc Linh }\end{array}$ & 10.17614 & 4.146 & .639 & .569 \\
\hline $\begin{array}{l}\text { SN3: Tôi cảm thấy áp lực xã hội khi mua } \\
\text { Sâm Ngọc Linh }\end{array}$ & 10.14773 & 5.189 & .447 & .692 \\
\hline $\begin{array}{l}\text { SN4: Những người tôi lắng nghe có thể } \\
\text { ảnh hưởng đến tôi mua Sâm Ngọc Linh }\end{array}$ & 9.93750 & 5.293 & .481 & .674 \\
\hline \multicolumn{5}{|c|}{ Nhận thức về kiểm soát hành vi (Cronbach's Alpha = 0.858) } \\
\hline $\begin{array}{l}\text { PBC1: Bản thân tôi quyết định có nên } \\
\text { mua Sâm Ngọc Linh hay không }\end{array}$ & 10.30682 & 6.031 & .704 & .818 \\
\hline $\begin{array}{l}\text { PBC2: Tôi có tiền để mua hàng Sâm } \\
\text { Ngọc Linh }\end{array}$ & 10.52273 & 5.771 & .720 & .812 \\
\hline $\begin{array}{l}\text { PBC3: Đối với tôi mua Sâm Ngọc Linh } \\
\text { rất dễ dàng }\end{array}$ & 10.53409 & 6.250 & .679 & .829 \\
\hline $\begin{array}{l}\text { PBC4: Đối với tôi, việc mua Sâm Ngọc } \\
\text { Linh là có thể }\end{array}$ & 10.55114 & 5.929 & .706 & .818 \\
\hline \multicolumn{5}{|c|}{ Ý định mua (Cronbach's Alpha =0.767) } \\
\hline $\begin{array}{l}\text { PI1: Tôi sẽ cố gắng mua Sâm Ngọc Linh } \\
\text { trong tương lai }\end{array}$ & 6.14205 & 3.677 & .554 & .735 \\
\hline $\begin{array}{l}\text { PI2: Tôi dự định mua Sâm Ngọc Linh } \\
\text { trong năm tới }\end{array}$ & 6.31250 & 3.439 & .615 & .669 \\
\hline $\begin{array}{l}\text { PI3: Xác suất tôi sẽ mua Sâm Ngọc Linh } \\
\text { trong mười hai tháng tới là cao }\end{array}$ & 6.47727 & 3.245 & .631 & .650 \\
\hline
\end{tabular}


Theo quan sát bảng trên, hệ số Cronbach's Alpha của các khái niệm là khá cao: khái niệm "Thái độ" có hệ số Cronbach's Alpha = 0.738; "Chuẩn mục chủ quan" có hệ số Cronbach's Alpha = 0.719; "Nhận thức về kiểm soát hành $\boldsymbol{v i}$ " $=0.858$; và "Ý định mua" có Cronbach's $\mathrm{Alpha}=0.767$. Các hệ số này hầu hết từ 0.7 trở lên chứng tỏ thang đo lường khá tốt. Hệ số tương quan biến - tổng của các biến quan sát trong bảng trên đều khá cao và cao hơn 0.3 . Tất cả các thang đo đều được chấp nhận và tiếp tục đưa vào phân tích nhân tố khám phá EFA.

\subsection{Phân tích nhân tố khám phá EFA}

Thực hiện phương pháp rút trích lần một rút trích được 3 nhân tố với tham số thống kê KMO $=0.817>0.5$ với hệ số Bartlett có mức ý nghĩa Sig. nhỏ hơn 0.05 nên đủ điều kiện để thực hiện phân tích nhân tố EFA.

Dựa vào dữ liệu xử lý, phần giải thích biến thì có 3 nhân tố được rút ra với hệ số Eigenvalue $1.222>1$ và 3 nhân tố này giải thích được $64.826 \%$ biến thiên dữ liệu.
Sau khi sử dụng phương pháp trích Principal Component với phép xoay Varimax, kết quả đạt được như sau: 11 biến quan sát của các biến độc lập được gom thành 3 khái niệm. Lần lượt xem xét sự phù hợp của các biến quan sát, ta thấy rằng biến quan sát $\mathrm{SN} 4$ có hệ số tải nhân tố nhỏ hơn 0.5 nên biến quan sát này sẽ bị loại.

Sau khi loại biến quan sát SN4 thì còn lại 10 biến tiếp tục đưa vào phân tích nhân tố lần 2 .

Sử dụng phần mềm SPSS để rút trích nhân tố, ta kiểm định hệ số $\mathrm{KMO}=0.808>0.5$ và kết quả kiểm định Bartlett's test cho thấy giá trị Sig. nhỏ hơn 0.05 , do đó với mức ý nghĩa là $5 \%$ thì các biến quan sát có tương quan trong tổng thể. Như vậy đủ điều kiện để phân tích nhân tố.

Dựa vào bảng giải thích biến thì có 3 nhân tố được rút ra, với hệ số Eigenvalue 1.206 >1và 3 nhân tố này giải thích được $67.332 \%$ biến thiên dữ liệu.

\section{Bảng 3. Ma trận xoay nhân tố}

\begin{tabular}{|c|c|c|c|}
\hline & \multicolumn{3}{|c|}{ Nhân tố } \\
\hline & 1 & 2 & 3 \\
\hline Thái độ của bạn đối với việc mua Sâm Ngọc Linh là tích cực & & .766 & \\
\hline Sâm Ngọc Linh là sản phẩm đáng giá & & .789 & \\
\hline Sâm Ngọc Linh là sản phẩm có lợi cho sức khỏe & & .781 & \\
\hline Bản thân tôi tự quyết định có nên mua Sâm Ngọc Linh hay không & .850 & & \\
\hline Tôi có tiền để mua hàng Sâm Ngọc Linh & .820 & & \\
\hline Đối với tôi mua Sâm Ngọc Linh rất dễ dàng & .786 & & \\
\hline Đối với tôi, việc mua Sâm Ngọc Linh là có thể & .785 & & \\
\hline $\begin{array}{l}\text { Hầu hết những người quan trọng với tôi nghĩ rằng tôi nên mua Sâm } \\
\text { Ngọc Linh }\end{array}$ & & & .854 \\
\hline Nhiều người xung quanh tôi có sử dụng Sâm Ngọc Linh & & & .828 \\
\hline Tôi cảm thấy áp lực xã hội khi mua Sâm Ngọc Linh & & & .517 \\
\hline Eigenvalue & 3.909 & 1.618 & 1.206 \\
\hline Phương sai trích & 39.091 & 16.182 & 12.058 \\
\hline Cronbach's alpha & 0.719 & 0.738 & 0.674 \\
\hline
\end{tabular}




\section{Phân tích nhân tố khái niệm "Ý định mua"}

Thực hiện phương pháp rút trích 3 biến quan sát với tham số thống kê $\mathrm{KMO}=0.689>0.5$ với hệ số Bartlett có mức ý nghĩa Sig. nhỏ hơn 0.05 nên đủ điều kiện để thực hiện phân tích nhân tố EFA. Dữ liệu xử lý cho thấy, có 1 nhân tố được rút ra với hệ số Eigenvalue 2.046 > 1 và nhân tố này giải thích được $68.194 \%$ biến thiên dữ liệu.

\subsection{Kết quả hồi quy}

\section{Bảng 4. Tóm tắt mô hình}

\begin{tabular}{|l|c|c|c|c|c|}
\hline Mô hình & $\mathrm{R}$ & R bình phương & $\begin{array}{c}\text { R bình phương } \\
\text { hiệu chỉnh }\end{array}$ & $\begin{array}{c}\text { Sai số chuẩn của } \\
\text { ước lượng }\end{array}$ & Durbin-Watson \\
\hline 1 & $.545^{\mathrm{a}}$ & .297 & .285 & .84557686 & 1.856 \\
\hline
\end{tabular}

a. Predictors: (Constant), Nhan thuc ve kiem soat hanh vi, Thai do, Chuan muc chu quan

b. Dependent Variable: Y DINH MUA

Bảng 5. Bảng ANOVA

ANOVA $^{b}$

\begin{tabular}{|l|l|r|r|r|r|r|}
\hline \multicolumn{2}{|l|}{ Mô hình } & Tổng bình phương & \multicolumn{1}{c|}{$\mathrm{df}$} & Trung bình bình phương & $\mathrm{F}$ & Sig. \\
\hline 1 & Hồi quy & 52.020 & 3 & 17.340 & 24.252 & $.000^{\mathrm{b}}$ \\
\hline & Số dư & 122.980 & 172 & .715 & & \\
\hline & Tổng & 175.000 & 175 & & & \\
\hline
\end{tabular}

a. Predictors: (Constant), Nhan thuc ve kiem soat hanh vi, Thai do, Chuan muc chu quan

b. Dependent Variable: Y DINH MUA

Nguồn: Tác giả điều tra và phân tích, 2019

Kết quả hồi quy cho thấy $\mathrm{R}^{2}$ hiệu chỉnh = 0.285 mô hình giải thích được $28,5 \%$ sự thay đổi của biến "Ý định mua". Kết quả kiểm định Durbin-Watson cho thấy mô hình không có tự tương quan. Kiểm định $\mathrm{F}=24.252$ với giá trị Sig. rất nhỏ, cho phép kết luận sự kết hợp giữa các biến hiện có trong mô hình hồi quy có thể giải thích được sự thay đổi của biến "Ý định mua", tức mô hình hồi quy tuyến tính phù hợp với tập dữ liệu ở độ tin cậy 95\%. Bảng dưới đây thể hiện thứ tự tầm quan trọng của các nhân tố giải thích cho biến "Ý định mua" căn cứ trên hệ số beta đã chuẩn hóa.

\section{Bảng 6. Kết quả phân tích hồi quy- "Ý định mua sâm Ngọc Linh"}

\begin{tabular}{|c|c|c|c|c|c|c|}
\hline \multirow[b]{2}{*}{ Mô hình } & \multicolumn{2}{|c|}{$\begin{array}{l}\text { Hệ số hồi quy } \\
\text { chưa chuẩn hóa }\end{array}$} & \multirow{2}{*}{$\begin{array}{l}\text { Hệ số hồi quy } \\
\text { đã chuẩn hóa } \\
\text { Beta }\end{array}$} & \multirow[b]{2}{*}{$\mathrm{t}$} & \multirow{2}{*}{$\begin{array}{l}\text { Mức ý } \\
\text { nghĩa } \\
\text { Sig. }\end{array}$} & $\begin{array}{l}\text { Thống kê } \\
\text { cộng tuyến }\end{array}$ \\
\hline & $\mathrm{B}$ & Sai số chuẩn & & & & Dung sai VIF \\
\hline Hằng số & $-2.282 \mathrm{E}-017$ & .064 & & .000 & 1.000 & \\
\hline Chuẩn mực chủ quan & .352 & .064 & .352 & 5.506 & .000 & 1.0001 .000 \\
\hline Thái độ & .293 & .064 & .293 & 4.577 & .000 & 1.0001 .000 \\
\hline $\begin{array}{l}\text { Nhận thức về kiểm } \\
\text { soát hành vi }\end{array}$ & .296 & .064 & .296 & 4.636 & .000 & 1.0001 .000 \\
\hline
\end{tabular}

a. Dependent Variable: Y DINH MUA

Nguồn: Tác giả điều tra và phân tích, 2019 
Cả ba nhân tố "Chuẩn mực chủ quan", "Thái độ", "Nhận thức về kiểm soát hành vi" có tác động lên ý định mua của người tiêu dùng đối với sản phẩm sâm Ngọc Linh. Trong đó, nhân tố “Chuẩn mực chủ quan” là yếu tố có tác động lớn nhất, đến nhân tố "nhận thức về kiểm soát hành vi" và nhân tố "Thái độ" ảnh hưởng yếu nhất đến "Ý định mua" của người tiêu dùng đối với sản phẩm Sâm Ngọc Linh.

\section{Kết luận và hàm ý chính sách}

\subsection{Kết luận}

Với xu hướng sử dụng thảo dược và nhu cầu tiêu dùng các sản phẩm dược liệu ngày càng cao, bài viết này đã xem xét hành vi của người tiêu dùng thị trường Kon Tum đối với sản phẩm Sâm Ngọc Linh theo kinh nghiệm sử dụng khung khái niệm của mô hình TPB (Ajzen, 1991). Kết quả đạt được từ mô hình đã chứng minh một sự phù hợp tốt, các thang đo đảm bảo độ tin cậy và 03 giả thuyết nghiên cứu được chấp nhận. Kết quả cũng chỉ ra rằng chuẩn mực chủ quan là yếu tố có ý nghĩa nhất, yếu tố quyết định quan trọng của ý định mua Sâm Ngọc Linh. Kết quả thu được từ nghiên cứu này đã khẳng định ý định mua Sâm Ngọc Linh chịu ảnh hưởng từ ý kiến khác thay vì tự quyết định của người tiêu dùng.

\subsection{Hàm ý chính sách}

Kết quả nghiên cứu đã cho thấy yếu tố chuẩn mực chủ quan tác động mạnh mẽ đến ý định mua Sâm Ngọc Linh của người tiêu dùng, do đó chính quyền địa phương, các doanh nghiệp và tổ chức, cá nhân cần xây dựng chiến lược truyền thông nhằm gia tăng ảnh hưởng của nhóm tham khảo bằng cách tăng cường các chiến lược tiếp thị truyền miệng, xây dựng và quảng bá các câu chuyện về Sâm Ngọc Linh thu hút sự quan tâm của người tiêu dùng, các hoạt động nhằm trải nghiệm sản phẩm thu hút sự tham gia và trao đổi giữa doanh nghiệp sản xuất và chế biến Sâm Ngọc Linh với người tiêu dùng. Mục đích quan trọng là gia tăng niềm tin cho việc sử dụng sản phẩm thông qua nhóm chuẩn mực chủ quan và dẫn dắt người tiêu dùng lựa chọn các sản phẩm thô và sản phẩm được bào chế để gia tăng giá trị Sâm Ngọc Linh.

Ảnh hưởng của xã hội rất quan trọng trong việc thay đổi nhận thức nhất là trong việc sử dụng dược liệu thay vì các chế phẩm hoá học để nâng cao sức khoẻ. Tuy nhiên rào cản ở đây không chỉ là nhận thức mà còn là yếu tố thu nhập bởi vì sản phẩm Sâm Ngọc Linh thô có giá thành cao. Hiện nay, mức độ tham gia vào chuỗi giá trị của Sâm Ngọc Linh còn hạn chế: Sâm Ngọc Linh chủ yếu vẫn được bán dưới dạng thô, chủ yếu dựa vào niềm tin của người mua và người bán là chủ yếu. Vì vậy đối với góc độ doanh nghiệp cần nghiên cứu các sản phẩm là chế phẩm Sâm Ngọc Linh để tạo ra giá trị gia tăng thay vì chỉ bán thô cho thị trường cao cấp nhằm thương mại hoá và phổ biến. Bên cạnh đó, các đơn vị sản xuất và kinh doanh phải xây dựng được thái độ tích cực của người tiêu dùng với sản phẩm, tạo niềm tin cho họ khi mua sản phẩm thông qua các công cụ hỗ trợ truy xuất nguồn gốc xuất xứ của sản phẩm.

Lời cảm ơn: Nghiên cứu này được tài trợ bởi Quỹ Phát triển khoa học và Công nghệ Đại học Đà Nẵng trong đề tài có mã số B2016DNA-21-TT. Nhóm tác giả trân trọng cảm ơn Quỹ phát triển Khoa học và Công nghệ Đại học Đà Nẵng đã tài trợ kinh phí để thực hiện nghiên cứu. Đồng thời cảm ơn ban lãnh đạo và đồng nghiệp Phân hiệu ĐHĐN đã hỗ trợ cung cấp thông tin, tạo điều kiện để nhóm tác giả hoàn thành tốt nghiên cứu. 


\section{TÀI LIẸU THAM KHẢO}

\section{Tiếng Anh}

Ajzen I. (1991), The theory of planned behaviour, Organizational behaviour and human decision processes, $50,179-211$.

Ajzen, I. (2002), Constructing a TPB questionnaire: Conceptual and methodological considerations.

Amran, A., \& Nee, G. (2012). Determinants of behavioural intention on sustainable food con- sumption among consumers of low income group: Empirical evidence from Malaysia, WEI International European Academic Conference Proceedings, Zagreb, Croatia, 84-93.

Chiew, S. W., Mohd, S. B. M. A., Norhayati, Z., Muhammad, N. M. T. (2014), Consumers Perception, Purchase Intention and Actual Purchase Behavior of Organic Food Products, Rev. Integr. Bus. Econ. Res, Vol 3(2), 378-397.

Dongmin, L., Seul, G. Y., Jaeseok, J., Junghoon, M., Gu, H. J. (2012), Market Segmentation Based on Attributes for the Purchase of. Fresh Ginseng, Agribusiness and Information Management, Vol.4 No.2, $1-13$.

First, I., \& Brozina, S. (2009). Cultural influences on motives for organic food consumption, EuroMed Journal of Business, 4, 185-199.

Fishbein, M. and Ajzen, I. (1975), Belief, Attitude, Intention, and Behavior: An Introduction to Theory and Research, Addison-Wesley Reading, MA.

Jain, S., Khan, M. and Mishra, S. (2017), Understanding consumer behavior regarding luxury fashion goods in India based on the theory of planned behavior, Journal of Asia Business Studies, Vol. 11 No. 1, 4-21.

Kim. H. and Karpova. E. (2010), "Consumer Attitudes toward Fashion Counterfeits: Application of the Theory of Planned Behavior", Clothing \& Textiles Research Journal, Vol.28 No.2, pp.79- 94.

Marija, H., Marina, J., \& Anita, F. I. (2015), The role of subjective norms in forming the intention to purchase green food, Economic Research-Ekonomska Istraživanja, Vol. 28, No. 1, 738-748

Michaelidou, N., \& Hassan, L. M. (2008), The role of health consciousness, food safety concern and ethical identity on attitudes and intentions towards organic food, International Journal of Consumer Studies, $32,163-170$.

Phuah, K. T., Rezai, G., Mohamed, Z., \& Shamsudin, M. N. (2012), Consumers' awareness and consumption intention towards green foods, African Journal of Business Management, 6, 4496-4503.

Saleki, Z. S., Seydsaleki, S. M., \& Rahimi, M. R. (2012), Organic food purchasing behaviour in Iran, International Journal of Business and Social Science, 3, 278-285.

Salleh, M. M., Ali, S. M., Harun, E. H., Jalil, M. A., \& Shaharudin, M. R. (2010), Consumer's perception and purchase intentions towards organic food products, Canadian Social Science, 6, 119-129.

\section{Tiếng Việt}

Nguyễn Việt Thiên (2017), Nghiên cứu phát triển bền vững Sâm Ngọc Linh ở tỉnh Quảng Nam, Luận án tiến sĩ nông nghiệp, Trường Đại học Kinh tế - Đại học Huế.

Quyết định số 31/2018/QĐ-UBND ngày 14 tháng 11 năm 2018 về sửa đổi, bổ sung khoản 1 và khoản 2 điều 1 của quyết định số 29/2011/QĐ-UBND ngày 26 tháng 9 năm 2011 của Uỷ ban nhân dân tỉnh về việc phê duyệt đề án xây dựng và phát triển các ngành kinh tế mũi nhọn và sản phẩm chủ lực của tỉnh đến năm 2020. 